\title{
MOVEMENT IN TRADITION: TOBE
}

\author{
by \\ Ebti Nabag \\ BA(Hons), University of Ontario Institute of Technology \\ Communication Studies, 2012 \\ A Major Research Paper \\ Presented to Ryerson University \\ in partial fulfillment of the \\ requirements of the degree of \\ Master of Fine Arts \\ In the Program of \\ Documentary Media
}

Toronto, Ontario, Canada 2016

(C) Ebti Nabag 2016 
MOVEMENT IN TRADITION: TOBE

I herby declare that I am the sole author of this MRP. This is a true copy of the MRP, including any required final versions.

I authorize Ryerson University to lend this MRP to other institutions or individuals for the purpose of scholarly research. I further authorize Ryerson University to reproduce this MRP by photocopying or by other means, in total or in part, at the request of other institutions or individuals for the purpose of scholarly research.

I understand that my MRP may be made electronically available to the public. 


\begin{abstract}
Movement in Tradition: Tobe is an installation project that explores the traditional Sudanese garment, the tobe, which is worn by Sudanese women usually after marriage. The project was begun in order to explore the current situation of the tobe in Canada, but quickly became an umbrella encompassing the past, present, and future of the tobe, the many layers this simple tradition has and the implications of changes in this tradition.
\end{abstract}




\section{Acknowledgment}

I would like to thank my primary supervisor, Katy McCormick for constantly challenging me by asking me difficult questions that allowed me to dig deeper into this project, and for helping me be more critical of this unique topic. I am also grateful for having Vid Ingelevics as my secondary supervisor. His guidance throughout my installation process will not be forgotten. Lastly, I would like to thank Blake Fitzpatrick for his constant encouragement and interest in this project.

Finally, this project would not be possible without the participants who have welcomed me in their homes and allowed me to record them, sharing their views and thoughts on this tradition. Thank you to; Najat Al-Zubair and Iman Hussain, Rihab Ayoub and Kamala Ramadan, Kawther Idris and Aida Elbadri, Magda Idris and Rana Abduljalil, Souad Abuzaid and Sarah Salih, Nahid Osman and Sara Elsadig. Words can't express how grateful I am. 


\section{TABLE OF CONTENTS}

DECLARATION …...........................................................................................................................

ABSTRACT …...................................................................................................................ii

ACKNOWLEDGMENT …….................................................................................................... iv

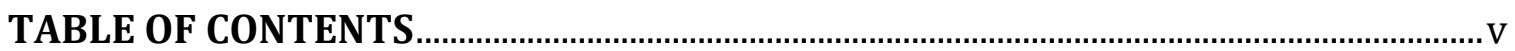

INTRODUCTION ................................................................................................................

CHAPTER 1: PROJECT DESCRIPTION AND BACKGROUND ............................................

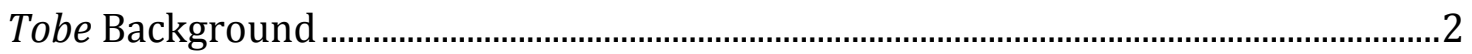

Personal Connection to the Project .......................................................................................4

Exhibition Description..................................................................................................

Cultural History Around the Tobe ……………………………………………………......

Unpacking the Interviews ...................................................................................................

The Rigid Process of Wearing the Tobe …………………………………………....

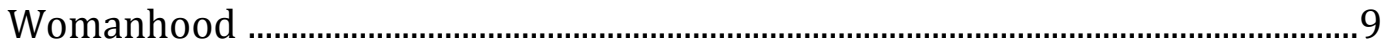

Influence of the Tobe on Sudanese Women ............................................................10

Uncertainty Embracing the Tobe ………………………………………………....13

Socioeconomic Status, and the Colonial Exchange …………………...................... 14

The Tobe as a Cultural Marker .....................................................................................

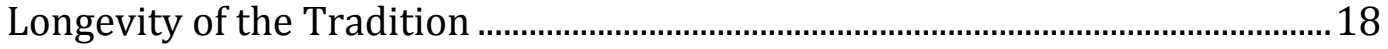

CHAPTER 2: DOCUMENTARY RELEVANCE ..................................................................18

Documentary To Me .................................................................................................. 18

Observational Documentary Video..................................................................................22

Relation to Other Documentary Work..........................................................................21

CHAPTER 3: METHODOLOGY ………………………………………………………..26

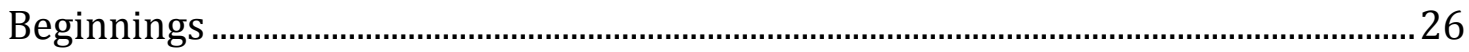

Researching the Tobe in Sudanese Community Through Conversation......................26

Observational Video Method ..............................................................................................2

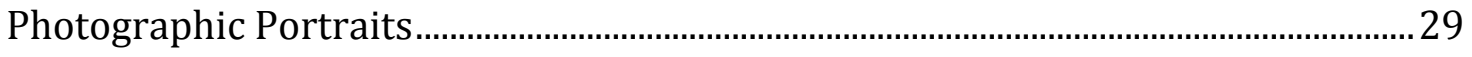

Portraits and Abstract Photos....................................................................................... 
First Installation Draft...................................................................................................

Resolving the Final Installation .....................................................................................

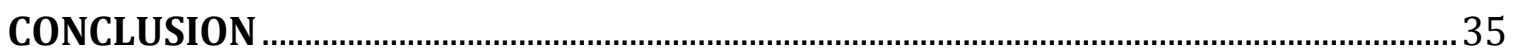




\section{INTRODUCTION}

Traditions are known to be customs, beliefs, statements, information etc., which are passed down from generation to generation by word of mouth or practice. One of the definitions of the word tradition in the English dictionary is: "A long-established or inherited way of thinking or acting." Another is, "A continuing pattern of cultural beliefs or manners." 1

The Merriam-Webster English dictionary defines tradition as: "The handing down of information, beliefs, and customs by word of mouth or by example from one generation to another without written instruction."2 The emphasis on "without written instruction" is very relevant in the context of this project. The project speaks to a generational story, the mother-daughter relationship, and a tradition that is to be passed down by the mother. Finding minimum written information on the tradition of the tobe and limited instruction on how to wear the garment leaves the mothers in charge of passing it down through practice. This also speaks to the mother-daughter relationship, where often mothers influence their daughters by leading by example or where their examples are rejected because of other factors.

The word tradition stems from middle French tradicion, from Latin tradition-, trāditiō action of handing over from tradere to hand over, betray- Traitor. ${ }^{3}$ It is of interest to me that when tracing the origins of the word tradition we find that it is derived from the word traitor. This suggests a contradictory reading where one could be denouncing one's tribal practices, history or origins.

\footnotetext{
1 tradition. Dictionary.com. Dictionary.com Unabridged. Random House, Inc. http://www.dictionary.com/browse/tradition (accessed: June 14, 2016).

2 tradition. Merriam-Webster.com. Merriam-Webster's Learner's Dictionary. http://www.merriam-webster.com/dictionary/tradition (accessed: June 14,2016).

3 tradition. Merriam-Webster's Learner's Dictionary. accessed: June 14,2016).
} 
Movement in Tradition: Tobe began with the question "Do first-generation young Sudanese-Canadian or Canadian-Sudanese women identify or connect to the tobe, a traditional garment Northern Sudanese women are expected to wear once married?" The question raised additional significant questions: Does the tobe represent the same values and connotations for the two generations, the mothers and the daughters? How do young women feel about the tobe, and why is it not as visible amongst the younger generation of married women as it is amongst our mothers? These questions opened the door for further exploration of the history of the tobe, revealing a multilayered and complex tradition.

In this paper I will be introducing the traditional Northern Sudanese garment the tobe. I will describe its cultural history, and its implications on three generationsfirst-generation Sudanese-Canadian women, which includes myself, our mothers who are born and raised in Sudan but migrated to Canada, and my grandmother's generation, which I will refer to as our ancestors, who were born, raised and continued to live in Sudan. I will then move into how my project sits within the larger spectrum of documentary, the project's documentary relevance and the method used to achieve the work, I will conclude with the outcome of the installation.

\section{CHAPTER 1: PROJECT DESCRIPTION AND BACKGROUND}

\section{Tobe Background}

The tobe, meaning "bolt of cloth,"' is a 15-foot rectangular material that comes in many vibrant colours, patterns, and beading. From the 1800s, and up to 1952, the standard tobe consisted of two pieces of cloth (four and a half meters each) joined by fine crochet. ${ }^{4}$ The tobe is an indication of marital status-in a cultural wedding ceremony, the bride is to wear a heavily beaded red tobe, which is often her first

\footnotetext{
4 Marie Grace Brown, "Fashioning their Place: Dress and Global Imagination in Imperial Sudan." Gender \& History 26 (3): 502-518.
} 
time wearing a tobe. Once the ceremony is complete the new bride is expected to wear the garment to the majority of her social functions. In the 1800s, regardless of marital status, the tobe was donned by women whose physical features matured, and therefore it was considered inappropriate for them to leave the home without being thoroughly covered.

The age of the woman plays an important role in which tobe is suitable for the woman to wear. Some are beaded, adding weight to the material and some are painted on with oil paint and glitter. Worn over one's clothes, usually a skirt and a blouse or a dress, one end of the fabric is placed on the right shoulder, or tied around the waist then wrapped around loosely covering the body from head to toe, resting the other end of the material on the left shoulder while leaving the face revealed (one should note that wearing the tobe backwards, resting the end of the garment on the right shoulder, is linked to non-Sudanese women who engaged in prostitution and were unfamiliar with wearing the Sudanese tobe. $)^{5}$ Chiffon tobes are known for their thin and slippery material. Heavily beaded chiffon tobes are mainly worn by newlywed or middle-aged women who are attending any form of celebration, while the elder women choose to wear a stiffer more stable fabric that is calm in colour with a reasonable amount of beading or stitching. Except the white tobe the design, colour and type of fabric are governed by the fashion stage the tobe is moving through. The white tobe is the preferred uniform for a woman working in a public institution and, while designs are subtle, the fabric of the tobe remains stable. The white tobe is also an indication of sorrow. A woman grieving the loss of her husband wears the white tobe until her legal mourning period is over. ${ }^{6}$ The tradition of strictly wearing the white tobe during grief has evolved and is not embraced by many women the way it was by our ancestors.

\footnotetext{
${ }^{5}$ Author in conversation with Najat Al-Zubair on, August, 2016. See Movement in Tradition: Tobe, 20:00, Digital video."

${ }^{6}$ Suad Salih, "Sudanese Toub: Renewable world despite typical design. "SudanNow Magazine. March 2013. Accessed June 15, 2016. http://sudanow.info.sd/sudanese-toubrenewable-world-despite-typical-design/. The Islamic legal mourning period for a woman mourning her husband is 40 days.
} 
The style and quality of the tobe is an important indicator of the economic status of the woman's husband, where the quality and the price of the tobe define the buyer. Therefore, it is a means of showing pride among women, particularly during social events where the women compete to wear the most fashionable tobe. ${ }^{7}$ Gifted by men or women, the tobe is recognized as the most significant gift to give a woman. In traditional Sudenese culture, it is the gift of value and appreciation. In its essence the tobe represents modesty, simplicity, and cultural identity.

The aforementioned are facts rooted in Sudanese culture that a Sudanese-Canadian such as myself can pick up on while observing the women and the tradition, yet, in my own personal research, the origins of these practices and connotations were never explored by the current generation of women in Canada, and were not communicated by the parents or grandparents living here.

\section{Personal Connection to the Project}

Movement in Tradition: Tobe originates in personal experience. The tobe is a garment that I was not able to identify with as a young girl. With time and age I started to recognize that my mother did not separate herself from the tradition even when here in Canada. She cherished the tobes my father gifted her, and he knew how valuable they were to her. Through time, I picked up on patterns and scenarios the tobe created that brought my mother, sisters and I closer. The process of her choosing a tobe for a social gathering was an event where she asked my sister and I for our opinion on which tobe to wear and how to match it. Ironing the 15 foot-long tobe was then a tedious job, especially for her; therefore I took it upon myself from time to time to iron the garment. Lastly, the way they are displayed in her closet is a clear symbol of how much the tobe is a part of her identity. When I picture my

7 Ibid. 
mother, I picture her in the tobe and what it representes to me: wisdom, modesty, and fashion-all a reflection of her.

My view of the tobe was challenged when a friend was preparing for her wedding. Conversations about whether she will be wearing a tobe after marriage elicited a defensive reaction. She was not pleased that her mother had already started purchasing tobes for her. It was the last thing she looked to have in her closet. I then noticed that not many first-generation newlyweds have worn a tobe to social gatherings and was curious about how this generation viewed the tobe.

I only began to notice how dear the tobe is to my mother after seeing the reaction of women from my generation to the garment. Our mothers do not only embrace the tobe, but they appear to see it as fundamental to the identity of a Sudanese woman. The complex layers of this tradition were revealed to me throughout the production of this project. My initial documentation of the tobe was motivated by the constant image of my mother wearing the garment, and how elegant and beautiful she made the tobe look, and the contrasting conversations that would take place with the younger, newlywed women. The project started to unfold beginning with the process of making still images of women moving in the tobe followed by mother and daughter interviews recorded and shot on video.

\section{Exhibition Description}

The project began by producing abstract images of the tobe. The photographs are captured in a way that exalts the tobe. They strip the tobe from its context to show a beautiful abstraction unbound from meaning. It is photographed against the sky, isolated from any human elements. This helped divert any presumptions that a viewer can have if the tobe is worn by a Sudanese woman and is then an obvious cultural symbol. Photographing it as an abstraction gives the audience the freedom to interpret the garment in any way they wish. My first photographs of the tobe were created to capture its beauty, something that we-the younger generationtended to overlook. The images became a conversation starter for the piece by 
raising questions about what this garment represents and why first-generation Canadian women have a tenuous relationship with the tradition. In this way, the abstract images of the tobe are the start of a multilayered, fascinating narrative that takes place between mothers and daughters around the tobe. This lead to the second component of the exhibition: which is a twenty-minute video of six mother and daughter interviews (interwoven with clips of the daughter tying on the tobe), that focus on, often for the first time, a free flowing dialogue about the tobe. The interviews unpack the many layers of this tradition. These conversations became the foundation of the project, revealing contrasting views between the two generations, as well as contrasting views between members of the same generation, and different sets of relations to Sudan. Seven themes became apparent in the interviews. They were: 1 ) The rigid process of matching and wearing the tobe; 2) Questions of whether the tobe symbolized womanhood or the completion of femininity; 3) The tobe as a cultural marker; 4) The tobe as a representation of socioeconomic status; 5) Influences and factors that played a role in reducing the appearance of the tobe among the younger generation; 6) Feelings of uncertainty, which speaks to where the younger women stand when it comes to accepting the tobe in the future or not; 7) The future generational longevity of the tobe. Throughout the interviews the evolution of the tobe revealed Sudan's political history.

Throughout the interviews and clips of the women wearing the tobe, often for the first or second time, you can pick up a lot on the mother-daughter relationship and the influence of the mother. There are moments where the daughter quickly rephrases her sentence because of a stare from the mother, or the look of frustration when the daughter kept putting the tobe on the wrong way, or the comment of the daughter saying, "Doesn't it look odd with pants?”, The mom quickly replying, "No. It's beautiful.", when ideally you would never wear pants with a tobe. But what continues to be refreshing to me is the unanimous proud feeling and look the mothers had when the tobe was finally on. 


\section{Cultural History Around the Tobe}

Marriage is a direct link to the tobe. This remained static throughout the generations. Marriage is a critical point of transition for a Sudanese woman. In that transition she moves from the home and protection of her father, to that of her husband. For that reason, a Sudanese woman's life is presumed to be proscribed by the domestic spaces she inhabits: namely the homes of her father and husband. ${ }^{8}$ As late as 1945, Sudanese girls married quite young; twelve-years old was considered "quite" a suitable age for marriage. ${ }^{9}$ Weddings were and remain extremely expensive. ${ }^{10}$ Men asserted their masculinity and preparedness for marriage by providing for their wives materially. In addition to a furnished house, which in theory belongs to the wife, ${ }^{11}$ Sudanese brides were presented with new sets of tobes, underwear, dresses, shoes and perfumes. This collection of gifts is called shayla (burden) or shanta (suitcase). This symbolizes the physical move from the house of her father to the care and protection of her husband.12 The shayla is mentioned in some of the interviews. It has changed through time. In the past the mothers received six to eight tobes. One of the married daughters speaks of receiving only three, while another one suggests she would rather the groom gift her things she can actually wear. ${ }^{13}$

Nahid Osman (mother): “...This is our culture. They gift 6, 8, 12. Whether you wear it or not...the groom is suppose to gift it." Sara Elsaddig (daughter): "He can get me something I'll wear."

\footnotetext{
8 Brown, "Fashioning their Place."

9 Sophie Zenkovsky, "MARRIAGE CUSTOMS IN OMDURMAN." Sudan Notes and Records 26, no. 2 (1945): 241-255, here p.241.

${ }^{10}$ For more information on dowry and wedding expenses see Zenkovsky, Sophie. "MARRIAGE CUSTOMS IN OMDURMAN." Sudan Notes and Records 26, no. 2 (1945): 241-245 $11 \mathrm{~J}$. W. Crowfoot, "Wedding Customs in the Northern Sudan", Sudan Notes and Records 5 (1922),pp.1-28, here p.1.

12 Brown, "Fashioning their Place."

${ }^{13}$ Author in conversation with Nahid Osman, Sara Elsaddig, Magda Idris on, August, 2016. See Movement in Tradition: Tobe (2016), 20:00, Digital video."
} 
Magda Idris (mother): “In our days we used to get 12 tobes. Rana had 3.”

The shayla is no longer what it once was. While the tradition of the shayla continues amongst the Sudanese-Canadian women (if married to a Sudanese) and the new generation of women in Sudan, the majority of brides are presented with monetary gifts, thus they have the freedom to pick and choose what appeals to them, leaving the tobe as an option and not a necessity.

\section{Unpacking the Interviews}

\section{The Rigid Process of Wearing the Tobe}

The mental process of deciding to wear a tobe is one kind of challenge but the physical process of putting on and wearing a tobe is a rigorous one. The colour of the tobe is to be matched with a top, or dress, jewellery, purse, and shoes, and a scarf, if you cover your hair. A new bride is expected to have decorative henna on her hands and feet. These steps also work to bring people together. My personal experience, which is echoed in other households, is my mother gathering my sisters and I for opinions on which tobe she should wear and how to match it. This process takes no less than ten minutes of bringing out multiple tobes with multiple blouses, shoes and purses to see which one complements the chosen tobe. While this process is time consuming, and I could never understand what difference it made whether the green blouse is a shade lighter or darker than the colour of the tobe, our opinion mattered to my mother and it brought her reassurance and joy. For me, my mother's obsession with the garment and seeing how elegant she makes the tobe look is what evoked my curiosity and built my appreciation for the garment.

This process has also been rejected by some women. Our ancestors donned the tobe in a simple fashion. It was not matched or embellished. A conversation between Kawther Idris and her daughter Aida emphasises this sentiment:

Kawther: “Even when I wear it, I don't match it to shoes, I don't match it to a top. Whatever comes, comes."

Aida: "Because this is the way you used to wear it?" 
Katwher: (nods) “I don’t do any matching." 14

\section{Womanhood}

Until the end of the nineteenth century, tobes only circulated in the hands of men. Fathers and husbands gave their daughters and wives tobes to mark important stages of their lives; the onset of menstruation, marriage and birth of a child. ${ }^{15}$ The connection to a woman's life cycle positions the tobe as a marker of marital wealth, but also of familial ties and gender roles.

In the interviews, the question of the tobe being a representation of femininity and womanhood received contrasting views. History indicates that the tobe acknowledged woman's social fulfillment to mature, marry, and produce offspring. ${ }^{16}$ The tobe then becomes a clear indication or suggestion that a woman is able to be married off, especially in the 1800s when girls wore the tobe at the sign of menstruation.

First-generation Sudanese women seem to feel discomfort around friends who accept the tobe and wear it during social events. Sarah Salih says , "I do associate the tobe with somebody at a different stage in life than I am." Another daughter, Sarah Elsadig says, "She's different. She's no longer one of us." Yet another, Kamala, adds, "She's a woman now." Interestingly enough, one of the mothers, Kawther Idris, does not associate the garment with women's obligation to marry and have children. The tobe to her is nothing but a fashion statement. Another mother, Rihab Ayoub, mentions the historical connotations the tobe is linked to by saying, "The tobe in the past represented coming of age and completion of womanhood." 17

\footnotetext{
${ }^{14}$ Author in conversation with Kawther Idris and Aida Elbadri on, August, 2016. See Movement in Tradition: Tobe, 20:00, Digital video."

15 Brown, "Fashioning their Place." p.120.

16 Ibid, p.120.

${ }_{17}$ Author in conversation with Sarah Salih, Sara Elsaddig, Kamala Ramadan and others in August, 2015. See Movement in Tradition: Tobe (2016), 20:00, Digital video.
} 
One should note that Sudanese society views marriage as the female's greatest accomplishment. A woman is only complete once married; career and education fulfilments are important but secondary. The tobe is a marker of a woman who is complete and secure. The garment itself can then work to segregate women and create feelings of discomfort.

\section{Influence of the Tobe on Sudanese Women}

To better understand the connection the mothers have to the tobe, one should refer to how the tobe positively influenced the life of the Sudanese woman, and worked to connect women from the home to public spaces. During the period of Imperial Sudan (1899-1956), a part of the British missionary reform aimed to civilize presumably oppressed women. Strict standards of honour, enclosure, female genital mutilation, ${ }^{18}$ and high literacy rates shaped imperial reform projects. Formal schooling for girls and informal schooling for housewives was implemented at the beginning of $1912 .{ }^{19}$ While the decision to send girls to school was criticized by religious conservatives, the main concern by the majority was how to protect the modesty and integrity of the woman as she traveled from the home to the school.

At the time, only married women donned the tobe, but in that moment the tobe was the answer that helped safeguard the honour and modesty of women as they walked from home to school, and that linked the women from the domestic space of the home to education. While this decision can be viewed as another way to regulate, constrain and have control over women, I believe most women viewed the tobe as their ticket to public spaces and continued to celebrate the garment.

\footnotetext{
18 For more information on the strict standards of honour and enclosed Northern Sudanese culture see Janice Boddy, "Wombs, and Alien Spirits: Women, Men, and the Zar Cult in Northern Sudan. "For female genital mutilation see Hayes, Rose Oldfield. "Female Genital Mutilation, Fertility Control, Women's Roles, and the Patrilineage in Modern Sudan: A Functional Analysis." American Ethnologist 2, no. 4 (1975).

${ }^{19}$ Brown," Fashioning their Place." p.122.
} 
Throughout these years the tobe-specifically the white tobe-became the uniform for students, teachers, nurses and midwives. It is evident that the garment granted women access to education and was no longer solely a marker of marital status and sexual reproduction. By the 1950s the white tobe was a symbol of a workingwoman and granted entry for women to enter into public spaces.

The tobe granted women access to public spaces but also served as a platform for women to express their political views. The process of naming each new style of tobe was an indicator of women being active participants in Sudanese society, a society that tried to exclude women from a rapidly changing Sudan. Specific tobe styles were given names that were reflective of life in imperial Sudan. ${ }^{20}$ Names such as Galam al Busta, "Post Office Pen" (1915), Rimush Awlad Burri, "Eyelashes of the Burri Boys" (1940s) a popular band at the time, "The Russian Satellite" (1960s), and "The Sound of Music" (1960s) ${ }^{21}$, all referred to popular culture. "The Doctor's Ribs" (1930s) referred to the first graduating class of Sudanese doctors from Kitchener Medical School.22 "The Diplomatic Corps," "The Political Corps," and "Administrative Corps," followed after Sudan's independence from Great Britain in 1956. ${ }^{23}$

The tobe helped expand physical boundaries, and due to it's popularity amongst the women, and the community and culture it created, the tobe was also embraced by women who did not attend school. For the first half of the twentieth century, women were banned from political participation. Women strategically and creatively named new styles of the tobe to enter into political conversation within Sudan and conversation about the larger world. This was a way for them to occupy the public and the political spaces that were dominated by men. In Fashioning Africa: Power and the Politics of Dress, Jean Allman writes that dress is an "enormously valuable yet largely untapped archive" that can teach us about "bodily

\footnotetext{
20 Ibid, p.126

21 Ibid, p.126

22 Ibid, p.126

23 Ibid, p.126
} 
praxis as political praxis." 24 The women were able to reference their political desire based on the name of the tobe they wore. As Allman mentioned, the tobes and their names can also be viewed as archival material highlighting the history of Sudan.

By 1970 the Islamic political movement became present, ruling the country under a combination of the heritage of Islamic law, and selectively retaining elements of English Law. Shariah law was made state law in 1983 by president Jaafar AlNumayri. ${ }^{25}$ With the Shariah law in place, women resorted to the "Islamic wear," which is the abaya and tarha (a long black dress and scarf). Women who continued to wear the tobe made significant modification in their attire. In place of the usual short sleeves smocks (showal) underneath their tobes, women began to wear anklelength robes which concealed most of a woman's body, even underneath the tobe. ${ }^{26}$ Victoria Bernal quotes one of the women living in Wad al Abbas village in Northern Sudan during the political shift, "People became Muslims. They used to go with short dressed, and the top [was] naked [underneath their towbs], but now they have learned better."27

In the mother-daughter interview, Najat Al-Zubair in conversation with her daughter Iman Hussain touches on the aforementioned.

Najat: “The Islamic movement came in ' 89 and influenced the younger women from that time. They were told to cover their hair. Eventually people started to give up the tobe."

In the unedited interview Najat expresses that, the tobe is indeed a modest dress and simultaneously is the Sudanese culture. Najat concludes, "Women thought

\footnotetext{
${ }^{24}$ Jean Allman, 'Introduction, in Jean Allman (cd.), Fashion Africa: Power and the Politics of Dress (Bloomington: Indiana University Press, 2004), pp.1-4.

25 Gabriel R. Warburg, "The Sharia in Sudan: Implementation and Repercussions, 19831989." The Middle East Journal (1990): 624-637.

26 Victoria Bernal, "Gender, Culture, and Capitalism: Women and the Remaking of Islamic

"Tradition" in a Sudanese Village." Comparative Studies in Society and History 36, no. 1 p.46.

27 Ibid, p.46.
} 
wearing the Islamic dress and scarf made them Muslims, but you were never against Islam in your white tobe."

\section{Uncertainty Embracing the Tobe}

A high level of education, and a diminished sense of enclosure is what firstgeneration Sudanese-Canadian girls are granted in the West. Education is a path to independence, whether monetary independence, ideologies or individual character building. For that same reason, it is good to note that, in Sudan, religious conservatives worried about the priority of educating women, especially beyond the primary level. ${ }^{28}$

A majority of the people in Sudan envisioned a country with the same governing system and perseverance Sudan was under during its imperial years, but a country that retained the outline of its culture and values. In the eyes of the mothers living in Canada, the daughters are presented with the ideal living situation in the West. Their reasons for migrating to Canada include: higher education, better employment opportunities living standards and healthcare. With that attained, the daughters are expected to hold on to their Sudanese culture and traditions while in Canada. The traditions become a reminder to their heritage and is their link to Sudan.

This is where feelings of uncertainty about embracing the tradition may arise. The Sudanese heritage does not occupy a large portion of the daughter's lives. The interviews show homes that are furnished in a Western fashion. In Canada and to those I interviewed, the presence of Sudan is mainly apparent in the dialect between some family members, usually when speaking to the parents, which is naturally interrupted by the English language. This is exemplified in the video. In the community in addition to the dialect, Sudan is apparent in the cultural interactions, music, and the visibility of the tobe and women having henna on. While this adds up to little formal exposure to the culture of Sudan, parents constantly reinforce the tradition verbally by praising it, or expressing disapproval of those who disregard it.

\footnotetext{
28 Brown, "Fashioning their Place," p.122.
} 
Finally, I would like to bring up identity, and how acquiring multiple identities, in this case Sudanese-Canadian, or Canadian-Sudanese, can play a role in the decision of embracing the tradition or rejecting it. Identity is a very nebulous dynamic-a fluid idea, that can be linked to generational change and relocation. Acquiring multiple identities allows the daughters interviewed to float from one cultural context to another. This generation of young women is aware of their Sudanese heritage (whether they practice it or not) but has amalgamated the western traditions into their daily lives, if not completely embraced it. This is the "bridge" generation, the generation that can identify as Sudanese-Canadian or CanadianSudanese, and use them interchangeably. It is normal for this generation to have feelings of uncertainty about whether they will carry this tradition forward or not. I believe the challenge here is for the parents. Accepting that this tradition might not be carried forward is accepting that their daughters carry a dual identity due to displacement. Viewing this dual identity as a positive and not the reason for abandoning ones heritage is something that I hope will be embraced by the parents.

\section{Socioeconomic Status, and the Colonial Exchange}

While connotations of the tobe shifted through time, so did its appearance and design. Most of the tobes in the 1940s and 1950s were white with subtle designs of stripes, dots, or texture of the material. From the 1940s to the 1960s, the finely woven white cotton 'Tootal' tobe, named for Manchester-based calico manufactures Tootal, Broadhurst, and Lee, set the standard for the highest quality tobe among the Sudanese elite. ${ }^{29}$ Switzerland is also one of the biggest producers of the Sudanese tobe, and is known for producing high quality tobes. ${ }^{30}$ In the installation of Movement in Tradition: Tobe, a white tobe from 1968 was displayed with the words "made in Switzerland" lightly printed on one end of the fabric. This tobe belongs to the mother of a women from the Sudanese Community, Alawya Al-Bakri, which further speaks to the intergenerational aspect of the project.

\footnotetext{
29 Brown, "Fashioning their Place," p.124.

30 Salih, Sudanese Toub: Renewable world despite typical design.
} 
Amongst the names of the tobes the mothers mentioned in the interviews, was the tobe risalat London, which means Message from London. During the 1970s, economic restrictions prevented the Tootal tobes from being sold in Sudan. ${ }^{31}$ Fortunate women had the Tootal tobe sent to them from London. It is important to note that by this time British cloth manufactures knew how meaningful and important the tobe was to Sudanese women. The involvement of the Tootal tobe manufacturer became evident when in the late 1950s the company solicited suggestions of tobe names from members of the leading activist group, the Sudanese Women's Union. ${ }^{32}$ This colonial exchange resulted in names such as Aspou Al-Mar'a "Woman's Week."33 This is reflective and touches on the work of Yinka Shonibare, a British-Nigerian artist who uses African textiles to speak to the colonial history between Africa and Europe. ${ }^{34}$ Shonibare reveals that the African textile is in fact printed fabric based on Indonesian Batik (sometimes referred to as Dutch wax). ${ }^{35}$ The British adopted the process and set up factories in the north of England where Asian workers printed English designs for the West African market. Shonibare highlights the cultural influences of European colonizers upon African civilization, but also rejects the one-way influence of colonialism knowing that British cloth manufactures went to great lengths to anticipate the desires of their distant consumers. The fabric itself employs multiple identities. It is a reflection or expression of how Europe envisioned Africa under pressure of capitalism and the influence of vested commercial interests. ${ }^{36}$ To highlight this colonial cultural exchange, it is interesting to note that the word Tootal (made by the Manchesterbased manufacture Tootal, Broadhurts, and Lee) has been embraced by Sudanese women and used in place of the word gumash 'material' of the tobe, such as, "The

\footnotetext{
31 Brown, "Fashioning their Place," p.124.

32 Ibid, p.127.

33 Salih, Sudanese Toub: Renewable world despite typical design.

34 Hynes, Nancy, and Picton John. "Yinka Shonibare." African Arts 34, no. 3 (2001): 60-95. 35 Ibid, 60-95

36 Christopher B. Steiner, "Another Image of Africa: Toward an Ethnohistory of European Cloth Marketed in West Africa, 1873-1960." Ethnohistory 32, no. 2 (1985): 91-110.
} 
tootal of this tobe is nice." I later learned that most of the women were not aware that the word 'Tootal' is the name of the manufacturing company.

Today, the design, beading, texture and colours of tobes are endless. Some women even have their tobes custom made. Considering the impoverished living situations of the majority of the population in Sudan, this of course is a luxury. A fashionable tobe in Sudan can range anywhere from 600-1000 Sudanese pounds which is equivalent to 127-212 Canadian dollars. During my 2015 visit to Sudan, in a tobe shop a woman asks the owner if he knows of any second-hand store that would purchase her used tobes. The owner replies, "No but you can donate them to this store around the corner." Upset the woman replies, "Donate what!, they're in great condition and some are only worn once." To my surprise, the rest of the women in the store weigh in on the conversation and their shared dilemma. This luxury market has worked its way into benefiting from the tradition and while doing so it divided the women in social events. This is highlighted in the interviews where, Nagat, Iman's mother mentions the white tobe:

Najat: "The white tobe is something we all wore." Iman: "Did that bring you guys closer?" Najat: "Yes, the white tobe provided equality." 37

For a modern take, Aida shares with her mother Kawther a story that took place on a social media site called Whatsapp, amongst a group of her Sudanese friends:

"She sent one of the pictures, apparently this one tobe... it was so much money." Aida continues, "They all wanted it, but only one of them could afford it. She told them she was getting it for her brother's wedding, and you can tell the other women wanted it but couldn't afford it."38

\footnotetext{
${ }^{37}$ Author in conversation with Najat Al-Zubair, and Iman Hussain in August, 2015. See Movement in Tradition: Tobe (2016), 20:00, Digital video."

38 Author in conversation with Aida El-Badri on, August, 2015. See Movement in Tradition: Tobe (2016), 20:00, Digital video."
} 


\section{The Tobe as a Cultural Marker}

The tobe, being the national costume for Sudanese women, is an automatic marker of one's nationality. The mothers remember a beautiful, more progressive Sudan, while generally speaking Sudan is not viewed in a positive light due to the 2003 Darfur genocide and ongoing ethnic tensions between the North which have been considered to be "Arab Muslims," and the South "African Christians,"39 its authoritarian governing system, ${ }^{40}$ and the limitations of basic living standards the majority of the population encounters. The tobe brought feelings of nostalgia, belonging, and honour, mostly to the mothers. A closer connection to the land and the tradition was elicited among them when speaking of the garment; a feeling that the daughters cannot completely identify with. The mothers hold on to a memory of Sudan that is far from what we have witnessed. It is a frozen memory of a time and a tradition.

Iman: "For whatever reason they encountered, some people think of Sudanese people as obnoxious, unorganized, etc., so when you put on a tobe, it's an automatic marker that I am Sudanese. And Sudan hasn't achieved much..." Her mom, Najat, expresses disapproval by slightly shaking her head and widening her eyes. Iman then quickly rephrases her last sentence adding: "I mean yes, in your day we've accomplished a lot." 41

Rana notes: "We are not as fixated on our culture, like, the Indians for example, you can see a sari anywhere." 42

\footnotetext{
${ }^{39}$ For information on the civil war see Natsios, Andrew S. "Beyond Darfur: Sudan's Slide toward Civil War." Foreign Affairs 87, no. 3 (2008): 77-93. http://www.jstor.org/stable/20032652.

${ }^{40}$ For information on the governing system of Sudan see Peter Kok. "Sudan: Between Radical Restructuring and Deconstruction of State Systems." Review of African Political Economy 23, no. 70 (1996): 555-62.
}

${ }^{41}$ Author in conversation with Iman Hussain on, August, 2015. See Movement in Tradition: Tobe (2016), 20:00, Digital video."

42 Author in conversation with Rana Abduljalil on, August, 2015. See Movement in Tradition: Tobe (2016), 20:00, Digital video." 


\section{Longevity of the Tobe}

The longevity of the tradition was a question I referenced earlier in this paper. While the interviews do not provide a definite answer to the question, when the younger women are asked if they will pass down the tradition to their daughters, they all seemed certain of doing so:

Aida: "I will pass it...I'll let Aaliyah and Amayah know what tobe is. They know about it right now."43

Sara S.: "I said that I didn't' really see myself wearing it that often, but I mean, culture is really important to me, so I want to promote it as much as I can if I have kids." 44

The mothers on the other hand were very doubtful of the tobe being passed down to newer generations and lasting much longer amongst them.

While there is a lot to deconstruct from the interviews, it's evident that the tobe is loaded with political, social, historical and cultural meanings. Overall the mother and daughter interviews present a generational story not only about the tobe, but also about the historical events that took place in Sudan. The transitioning of the garment can be placed on a timeline alongside the history of pre-imperial Sudan, imperial Sudan, Islamacized Sudan, and now showing the evolution of the tobe. Furthermore, this video and its content draws on the mother-daughter relation, identity and displacement, nostalgia and memory and the transition of tradition through the passage of time.

\section{CHAPTER 2: DOCUMENTARY RELEVANCE}

\section{Documentary To Me}

43 Author in conversation with Aida El-Badri on, August, 2015. See Movement in Tradition: Tobe (2016), 20:00, Digital video."

${ }^{44}$ Author in conversation with Sara Salih on, August, 2015. See Movement in Tradition: Tobe (2016), 20:00, Digital video." 
Documentary to me is about bridging the gap between people. It is one more bridge between people who otherwise would not understand one another. As a documentary maker, it is important for me to tell the stories of the average individual who is less likely to be heard or seen, yet they have compelling stories that should be shared with a large audience. It is about having the average human being share a story that leads to a larger narrative that educates, creates awareness and exposure and sparks a dialogue. This is what I hope Movement in Tradition does. In addition, this work helped connect me to my heritage. Exploring the tradition of the tobe further led to intensive research and conversation with women and men, and that tapped into the history, politics, customs, and traditions of Sudan. Many of which I heard previous generations speak of but never explored myself.

Documenting the shared experiences and ideas about the mother and daughter relationship over a discussion about tradition, where the tradition can be viewed as a bridge between the two, is a way for those who are not of Sudanese origin to feel connected to the piece. Often, viewers noted the undeniable magnetic relationship the mothers and daughters had in the video, and how I was able to capture it on camera. A viewer who was not of Sudanese heritage questioned whether the video created tension between any of the mothers and their daughters. While this questioned reassured that women from other ethnicities could identify with the mother-daughter relationship the video depicts, it also made me grasp the affect my role as a domestic ethnographer had on this project. The participants in the video were able to freely interact with me, allowing their authentic selves to be captured in the video.

It is also a generational story about our ancestors, which is not casually shared unless there is a conscious effort put towards asking the right questions. This curiosity from the younger generation is something that brought forth excitement and nostalgia from the mothers. The project also chronicles the tobe at its current stage, revealing a fragile tradition. 
Throughout this project I also bridged a gap between myself as a Canadian and as a Sudanese.

\section{Observational Documentary Video}

The interviews are conducted in an observational documentary style leaving the voice of the interviewer out, and capturing only the interaction between the mothers and daughters. The end result is a video with no voice-over, no supplementary music or sound effects, no intertitles, and no behaviour repeated for the camera. This mode of documentary reveals and heightens aspects of characters and individuality, ${ }^{45}$ which becomes evident in the video.

This documentary style poses a series of ethical questions; one key question being: to what extent can a filmmaker explain the possible consequence of allowing behaviour to be observed and represented to others? ${ }^{46}$ Having this be an ethnographic video, which is susceptible to the notion of exoticism, the colonial gaze or misrepresentation, seeking out parts of the interviews or observational clips of the daughters putting on the tobe that may posses qualities that fascinate the viewer for the wrong reason was something I battled with during the editing process. Furthermore, editing dialogue through talking heads and creating a fragmented but coherent video can also be pieced with a particular outcome in mind. The interoperations of events may be rendered to seem trustworthy or untrustworthy. As a documentarian, being conscious to not manipulate the sentences and meaning of what the subject is sharing is something I do not take lightly. It is important for me to honour the subjects and create work that is not influenced by my own biases and expectations. Yet, it is my own heritage and I too face the same questions as my subjects. Thus, I am coming at the issues as an active insider. To put these ethical

\footnotetext{
${ }^{45}$ Bill Nichols, "What Type of Documentary Are There?, Introduction to Documentary. Indiana University Press, (2001): 99-135. p.111.

46 Ibid.
} 
concerns to rest, consent from the participants prior to filming and after the final edit is something that I request.

\title{
Relation To Other Documentary
}

The documentary work of Zineb Sedira references cross-cultural identity, language, memory and diaspora. Mother Tongue (2002) by Sedira is an interview based installation that explores three generations of Sedira's family, each communicating in their own "mother tongue," which they find difficulties with due to the different landscapes each one grew up in. Sedira says in an interview with Joseph McGonagle when asked about her decision to include her mother and daughter in her general documentary practice:

\begin{abstract}
"So, the idea of language, generational transmission, and translation started to interest me: the way we speak the way we are, the way we think, and even the way we dress. I was fascinated by the fact that in the same family-composed of three generations - there were three countries of birth and three languages. My mother was born in Algeria and speaks Arabic, my daughter was born in England and speaks English, and I was born in France and speak French. The idea of taking photographs of my mother, my daughter, and myself came about because I wanted to represent women within the same family through their body language and clothing." 47
\end{abstract}

Originally from Algeria, Sedira's parents moved and lived in France for economic reasons, but due to the poor treatment of North African immigrants by the French, Sedira's mother rejected the French language and their behaviour. North Africans were used as cheap labour and had experienced a lot of racism. The French also divided the Algerians by favouring Christian and Jewish Algerians by granting them French citizenship but not the Muslims. ${ }^{48}$ Similar to Movement in Tradition this

\footnotetext{
${ }^{47}$ Joseph McGonagle, and Zineb Sedira, "Translating Differences: An Interview with Zineb Sedira." Signs 31, no. 3 (2006): 617-28. p.618.

48 For quote from Zineb Sedira about the work see, Brandt, Amy, "Zineb Sedira", Brookyln Museum, https://www.brooklynmuseum.org/eascfa/feminist_art_base/zineb-sedira (accessed June 14,16).
} 
project brings forth historical events in Algeria and France and brings forth a political history.

Sedira later on moved to England where she had her daughter. Therefore Mother Tongue has three generations speaking three different languages, doing their best to communicate directly through words. In the first video the mother is communicating to Sedira in Arabic while Sedira replies back in French. The second video is of Sedira speaking French to her daughter as her daughter replies in English. The third and final video is where language becomes a communication barrier between the grandmother and Sedira's daughter. The grandmother is speaking to her grandchild in Arabic and is not able to elicit a response.

Through her domestic ethnographic documentary work Sedira was able to learn about her parents involvement in the French-Algerian war. Domestic ethnography work engages in the documentation of family members, or people with whom the maker has maintained long-standing everyday relations and has thus achieved a level of casual intimacy and a peculiar sort of reciprocity ${ }^{49}$. It contradicts the idea of ethnography which studies different cultures from the film makers own, yet also is concerned with the documentation of the lives of others coupled with selfinterrogation. Domestic ethnography is a term for documentary film types that function as a vehicle for self-examination and a means through which to construct self-knowledge through recourse to the familial other ${ }^{50}$. It is also placed in the realm of autobiographical practice.

In Mother, Father and I (2003) she discovers that her parents were freedom fighters during the war, yet her and her siblings had no idea how much their parents were implicated in the war. Three hours of footage was condensed to a twenty minutes interview video for each parent where she edited the sound of her voice out but

\footnotetext{
49 Michael Renov, "Domestic ethnography and the construction of the 'other'self." Collecting visible evidence 6 (1999): 140-55.

50 Ibid
} 
included herself listening visually to her parents. ${ }^{51}$ The result: a lot of tears and painful memories resurface.

As a domestic ethnographer, Sedira finds herself as an outsider/insider. Her familial ties give her complete access as an insider examining her parents for self-knowledge and allows for a unique unbound exchange. As Michael Renov explains, "This mode of ethnography, the desire for the other is, at every moment, embroiled with the question of self-knowledge; it is the all too familiar rather than the exotic that holds sway." 52

South African Zanele Muholi's photographic portraiture work Faces and Phases (2009) is a growing archive that documents the lives of black lesbian, gay, bisexual, transgender, and intersex (LGBTI) community in South Africa. Muholi is a selfproclaimed visual activist who also describes herself as an "insider" by virtue of her growing up in a homophobic South African township, but also locates herself as an "outsider" because of her exposure and access to economic, cultural and educational privileges which are not afforded to most black lesbians who have grown up in poor, and often dangerous South African townships. ${ }^{53}$ Through her insider/outsider position, Muholi is able to make the violence and segregation of the South African LGBTI community visible without the fear of speaking for the "other". Having experienced similar hate crimes and isolation as her participants, there is a high level of mutuality between Muholi and the participants. The shared experience allows for trust and content from the participants that otherwise could be difficult to share with an outsider. Muholi is there to empower the community and her presence is received in a positive light by the participants and the public. She is a member of the community and not a privileged outsider who is there to "examine"

\footnotetext{
51 Joseph McGonagle, and Zineb Sedira, "Translating Differences: An Interview with Zineb Sedira." p.619.

52 Michael Renov, "Domestic ethnography and the construction of the 'other'self." Collecting visible evidence 6 (1999): 140-55.

53 Nadine Lake, "Black Lesbian Bodies: Reflection on a Queer South African Archive. Africa Insight” vol.44(1), (2014) 69-83. p. 72.
} 
or "save" the LGBTI community in South Africa. Muholi has avoided two problems that can occur when speaking for others, first, the systematic divergence in social location between speakers and those spoken for which will have a significant effect on the content of what is said; and second, the practice of privileged persons speaking for or on behalf of less privileged persons which has actually resulted (in many cases) in increasing or reinforcing the oppression of the group spoken for. ${ }^{54}$

I used the works of these female documentarians as a point of departure for my own work. Employing the role of the domestic ethnographer in my own work (documenting people I have established a close relationship with who share the same ethnicity and culture) and being an active participant in the Sudanese community, allowed me to gain the trust, and comfort of the mothers and daughters. My insider/outsider position, "insider" being a female of Sudanese descent who shares the same language, and is aware of the traditions and customs, who also maintained a level of casual intimacy with the mothers and daughters, but also an "outsider" due to my upbringing in Canada and not absolutely identifying with the tradition explored in the project creates an environment of trust and mutual purpose. My curiosity is not driven by exoticism, but self-knowledge and is welcomed by the participants. It occurred to me that, the unique position of resembling the daughters in physical features, age, language and generation, allowed the mothers to treat me in a mother-daughter way. As I mentioned earlier, my role as an ethnographer, insider/outsider, helped create an amicable environment for both the participants and me. Similar to Sedira, this project was an educational one for myself. The visuals and interviews led to intensive research about the tradition of the tobe giving me a better understanding of Sudan and my heritage.

Community was also a very significant piece to this project. The way Muholi strives to ensure there is black queer visibility and a tangible archive of the LGBTI community in South Africa, Movement in Tradition worked to bring exposure to a

\footnotetext{
${ }^{54}$ Linda Alcoff, "The Problem of Speaking for Others." Cultural Critique, no. 20 (1991): 5-32, p. 7.
} 
culture and community that is not visible in Canadian society. Having witnessed the large presence of the Sudanese community at the opening night of MIT and the private listening session, the importance of community alongside pride and exposure became very relevant to the project. Indeed, it enabled [me] the viewer to image how people connect with, and belong to, their communities and nations. ${ }^{55}$ In this particular context, I align myself with the viewer (those identifying as Canadian) and place myself as an outsider, because in public, and in the gallery setting, I embody the Canadian identity where I naturally belong to the environment I am in. Viewing the overwhelming number of women in their tobes on opening night made me realize the importance of community and that this project is ultimately for them. It was also interesting to see that as a collective, the women felt empowered to wear the tobe in a public space (the gallery) that otherwise they would not be comfortable wearing on their own. Some freely moved in the space while others stayed closer to the video installation for what I viewed as a sense of belonging to the installation.

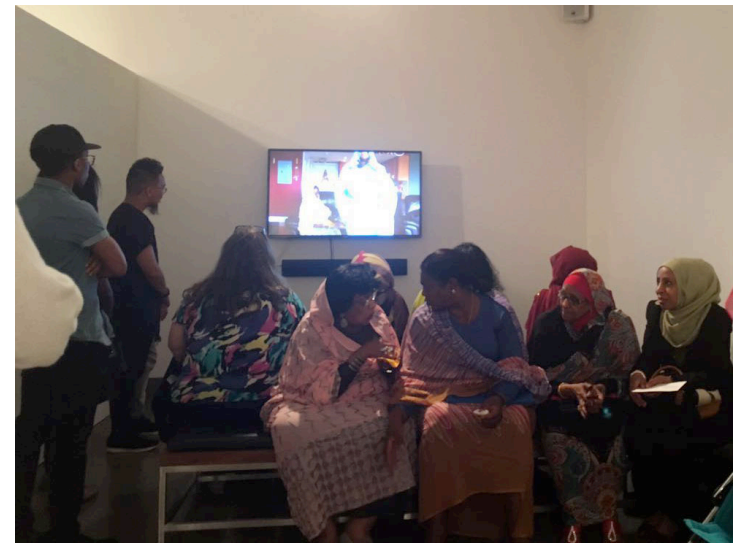

Figure 1: Movement in Tradition:Tobe, opening 2016 (C)Anandana Kapur

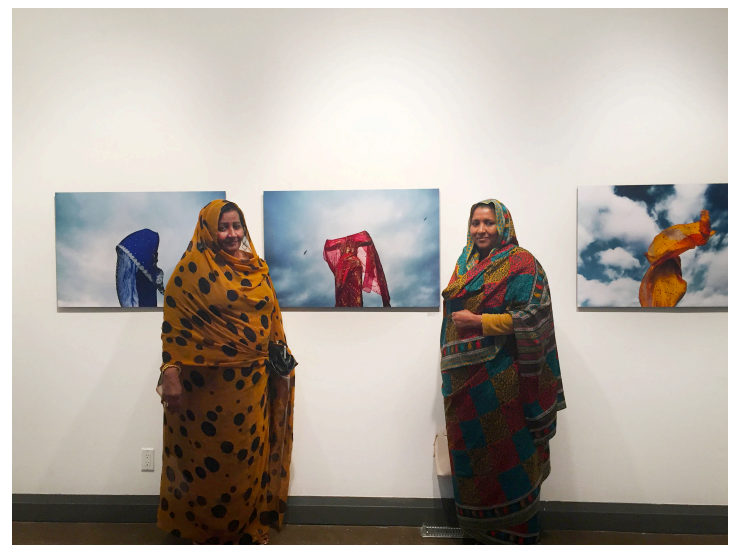

Figure 2: Movement in Tradition:Tobe, opening 2016 (C)Author

55 Rael Jero Salley, "Zanele Muholi's elements of survival." African Arts 45, no. 4 (2012): 5869 , p. 58. 


\section{CHAPTER 3: METHODOLOGY}

\section{Beginnings}

As indicated above, I began by photographing my mother's tobes for a book. I photographed the tobe as an abstraction. Despite her absence in the photographs, the images were a celebration of my mother.

\section{Researching the Tobe In Sudanese Community Through Conversation}

Being active in the Sudanese-Canadian community, I was often surrounded by Sudanese-Canadian women in their early- to mid-twenties. In one conversation, my newly-engaged twenty-six year old friend said, "My mom is buying me tobs, and I told her to stop." I sat back and observed her disapproval of her mother's action. I decided to explore her reaction further, and to see if other young newlywed women felt the same way. In any given gathering, while in the presence of a young Sudanese newlywed or engaged women, I would casually ask a question about the tobe, and observe their reaction. I would simply ask one of the following questions "Did you get any tobs?" "Are you going to wear a tobe after the wedding?" and let the conversation begin. To my surprise the energy in the room automatically shifted and became intense. Everyone had a comment and a point to make. They all followed a similar path, "Why are we expected to wear it." "I can't picture you in a tobe." "My mom keeps buying them, I don't know what to do." The back and forth was energetic and intriguing, and I felt the need to explore the tobe further.

Discussing this with my group of friends was not enough. I needed to make sure this was a relevant topic that had substance. I continued using social gatherings to test the importance of the tobe to the Sudanese woman. I decided to bring this same inquiry to the elder women, our mothers. At community events, or when friends of my mother visited, I once again asked questions pertaining to the tobe. This time around the questions were, "When did you first wear the tobe?" "How many did you get as a bride?" and "How do you feel about newlywed younger women not wearing 
it?" The last question in particular seemed to provoke the women. Aside from that, I recognized the joy and excitement the women exhibited when speaking about the tobe. They looked forward to sharing knowledge about this tradition when asked; They just needed someone to open the door and, give them a platform for this conversation.

I continued to take advantage of social gatherings to insert a comment about the tobe and observe the reactions. The conversations ranged from young women who are first-generation Sudanese-Canadians, to the elder generation and even made their way between the first-generation of women and the first-generation of men, thus sparking an even more interesting and heated dialogue. Some men associate the garment with their mother and aunts. Out of respect, a woman in a tobe is always referred to as khalto, meaning aunty. "You're going to be a khalto?" one of the men asked, and the women wasted no time getting offended.

Overall, this was my way of validating this project and reassuring myself of its importance within the Sudanese culture - both here and abroad.

The conversations I had with the two generations of women were the driving force behind the next artistic element, which became a conversational video between mothers and daughters discussing the tobe. I took my own conversational process of exploring the tobe between the generations and employed it with the women, creating a dialogue between the generations. The interviews delved deeper into what the tobe is and what it represented, opening up a larger dialogue revealing the history of the garment, and contrasting views between the generations.

\section{Observational Video Method}

Coming into the project (and program) as a photographer, incorporating a video piece was challenging. Prepping for sound and lighting were key elements in achieving high quality interviews but creating an environment that allowed the subjects to feel comfortable and relaxed was key to the power of the videos. Their 
comfort on screen and exuberance was contagious for those who viewed the videos. These interviews were meant to engage the mothers and daughters in a generational story elicited by the tobe, and speak to the mother-daughter relationship. They were to be observational interviews continuing with the technique I used in gatherings, of me asking a question and observing a reaction.

The interviews took place in the living room, on a two-seat sofa, placing the mother and daughter within close proximity to one another. This made for continuity when viewing the interviews as one continuous video, but moreover picks up on the domestic and cultural reference of the home.

Aside from the interview pieces, I filmed the daughters trying on the Sudanese tobe and filmed their interaction with their mothers and the garment. Here, I requested the mothers to bring a few of their tobes and with no preparation I asked the daughters to put on one of the tobes. At this point in my process the two videos (video 1, Figure 3) interview, (video 2, Figure 4) daughters wearing the tobe, were envisioned to play as two separate one-channel videos in a gallery.

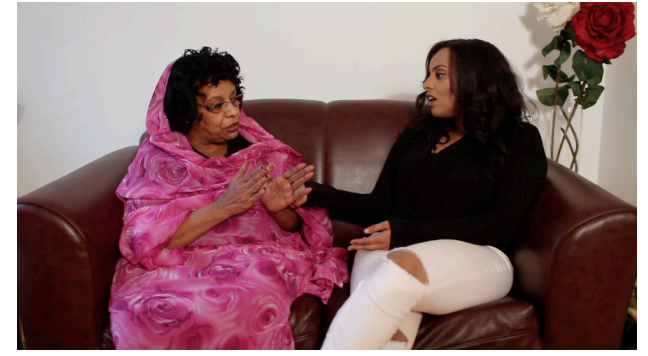

Figure 3: Najat Al-Zubair and Iman Hussain Video still, interview.

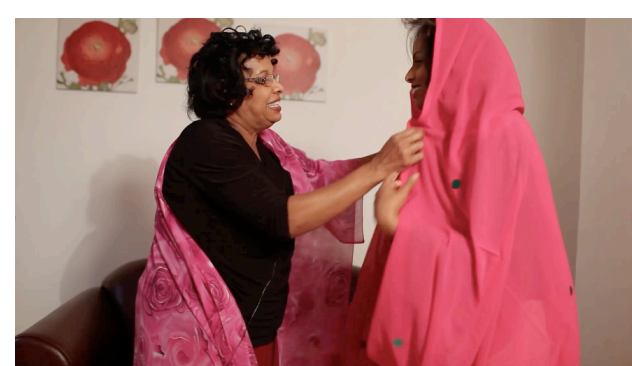

Figure 4: Najat Al-Zubair and Iman Hussain. Video still, wearing tobe.

The interviews resulted in seven themes outlined in the first section of this paper and the clips are full of information about the tobe, revealing much more than the abstract images did.

I combined the interview themes together, which expanded the first video to twenty minutes. This I thought was lengthy for a video installation. The second video was 
edited to be six minutes. It is a fast paced video with more movement and interaction between the women in comparison to the sit down interviews. The sequences of the second video worked well together. They accentuated the motherdaughter relationship even more. The transitions and humour in them allowed me to create a piece with a lighter content.

\section{Photographic Portraits}

At the conclusion of each video interview, I took individual photos of the mother and daughter. These were full body portraits of the mothers in their tobe, and the daughters in their Western clothes. They have the appearance of being extracted from the videos, each woman confronting the viewer, claiming her own individual space. In the gallery, I planned at that time in the process to group the portraits of the mothers on one wall, facing the portraits of the daughters. The portraits are subdued in comparison to the vibrant abstract images I described earlier. My approach here is reflective of the stage I consider the tobe to be in. The tradition seems to be losing its place in our culture. It is not what it once was, and may continue to decline until it is abandoned by newer generations. The intentional lack of vividness in the portraits is meant to move the audience to a recognition that this beautiful garment is slowly becoming less relevant to young Sudanese women. For the daughters and young Sudanese women, the portraits of the mothers serve as a memory and direct link to their mothers. These images serve as a representation of both generations' engagement with the tobe or lack of it.

Subsequent discussion around whether both portraits of women, the mothers and the daughters, need to be included in the space raised questions about who and what the project is about. The portraits of the mothers are very honorific, as they proudly display the tobe. Displaying their portraits without the daughters makes this a project solely about the tobe. Incorporating both portraits of the mothers and the daughters in the gallery emphasizes the generational story while keeping the tobe in the center of the project. I explored this concept further at the time but made 
a decision to display both portraits to honour both generations and the story of the mother-daughter relationship.

\section{Portraits and Abstract Photos}

As mentioned earlier, next to the abstract images the portraits are subdued. They communicate two opposing feelings and aesthetics. Bringing both set of images into a gallery space is a challenge. They speak of two different visions and don't interact well. At the time I envisioned the work in one open room. The video being the main piece did not seem to fit well with the vibrant abstract images. The portraits complemented the videos much more and for that reason I removed the abstract images from the exhibition.

\section{First Installation Draft}

At that time, the installation included two separate, one-channel videos, and the portraits of the mothers and daughters, which equalled to 12 images in total. The interview video was to be projected on the wall, which brought forth challenges of light spillage onto the projection from other places in the room. For the second video, a small monitor would be placed with headphones for personal viewing.

\section{Resolving the Final Installation}

The editing process and having people view the work was endless. During an earlier critique a professor mentioned weaving in the interview video with the video of the daughters trying on the tobe. That idea was dismissed, because the sequence of them wearing the tobe worked very well and received a positive reaction from viewers. The more time I spent watching and editing the interview pieces the more loaded with information they seem to get. Each clip touched on a different theme. The information started to become overwhelming as the video became lengthier. 
Similar to the interview video, the second video also needed to be experienced collectively and not on a separate monitor with headphones. These observations led to another experimental edit. Combining the two videos together, I used the video of the women wearing the tobe to break up the interview video, separating each interview theme by a clip of the daughters putting on the tobe, which kept building on the previous clip until the tobe is completely worn by the younger women to conclude the video. This edit gave the audience room to digest the information received from the interviews, and allowed for a more balanced piece. It also helped break up the interviews into chapters, slowly progressing alongside the video of the women putting on the garment. This also eliminated the need for an additional monitor with headphones in the space.

As further discussions took place, the inclusion of the portraits of the women was put into question. The aesthetics of the portraits in terms of lighting, cropping and continuity resulted in poor production and sequencing. Furthermore, the images of the women mimicked what the video achieved, which did so arguably better than the portraits. The video is more of an accurate portrayal of the women. The images presented stiffly posed women in comparison to the relaxed interactive personalities of the women that the video was able to show. This is the result of not spending as much time capturing their portraits as I did with filming the videos. I did not allow for enough time to capture the essence of the women, to gain their trust behind the lens and let their personalities come through the lens. This was one of the most valuable pieces of feedback and lesson from Susan kae Grant. While I was not content with the aesthetic of the portraits I still held on to them, but an honest critique helped reaffirm my thoughts and accept that they can be improved. The video piece is ultimately a more accurate portrait of the women and I came to accept that the still images were redundant.

With the portraits out of the installation there was a chance to revisit the abstract images. The abstract images were the starting point of this project. They opened the door for the conversational element, the videos. Their abstract form elicits 
questions, curiosity, and obscures the complex layers of the tobe. Bringing them back into the installation was again under consideration, but to be successful in revealing what the images stand for they would have to be viewed separately from the video piece. For this reason building a viewing station for the video in the gallery would maximize the experience of both the abstract photos and the video piece. This gives the audience time to spend with each component of the exhibition, starting with the abstract images, followed by the video.

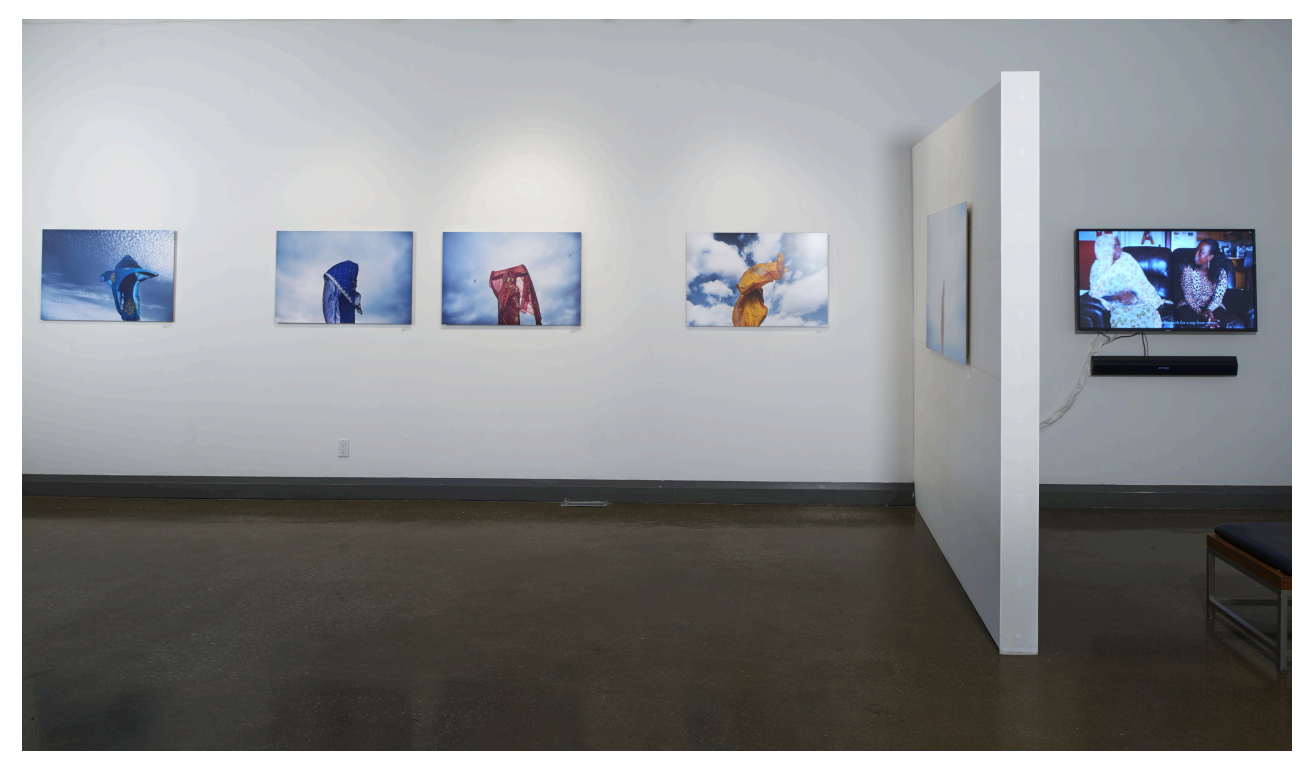

Figure 5: Movement in Tradition: Tobe, installation (CMartin Franchi

Out of 20 abstract images, a total of five carefully selected images were featured in the final installation. Two sequences of images with similar skies are paired and displayed within close proximity, while the other two are on either side of those all standing at $24 \times 36$ inches. The fifth image, $30 \times 45$, is placed separately concluding the series. The figure behind the tobe is not apparent in the first four images, as it is in the last one. 


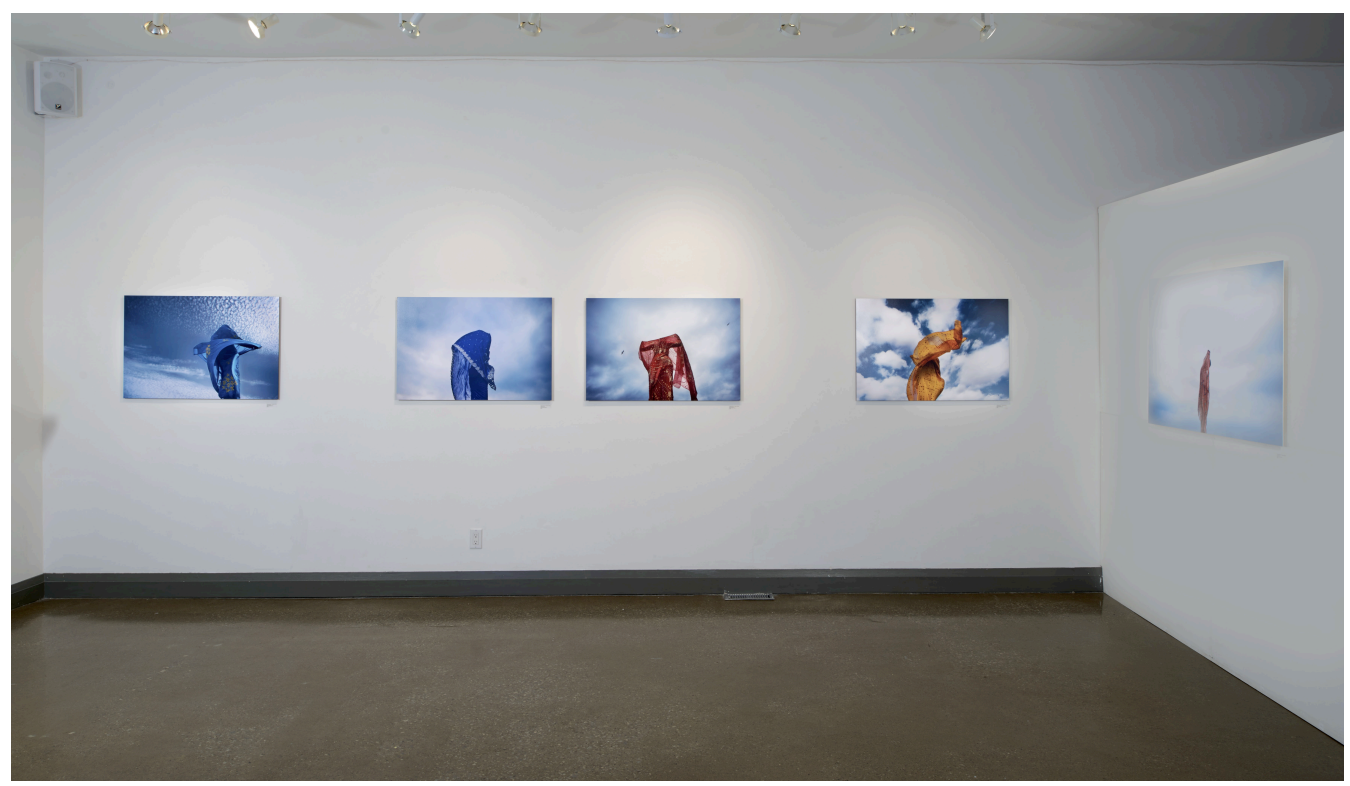

Figure 6: Movement In Tradition: Tobe, installation @ Martin Franchi

The video shifted from a projection to the use of a 49-inch monitor. A bench was provided in the video station that encouraged the viewer to take a seat and spend time with the video.

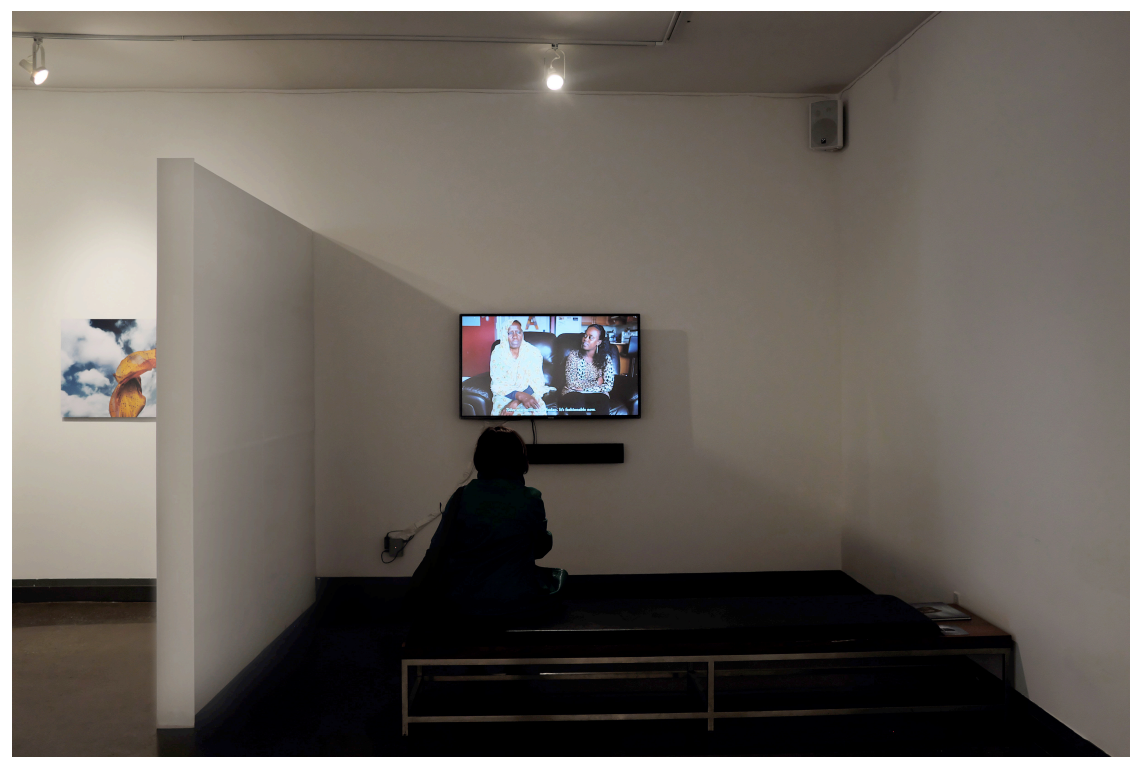

Figure 7: Movement in Tradition: Tobe, video installation (Cauthor

A final subtle piece to the exhibition was added to honour my mother, the motivation behind this project. Incorporating the actual garment in the installation 
was thoroughly discussed amongst myself, professors, and peers. I was fixed on the idea that the tobe would be seen as worn by the women during the exhibition, and that was how the garment would enter the gallery in its actual form. Later on, I felt that the project and exhibition included too little of my mother's influence on me and the project. Therefore, I decided to display her tobes in the same manner she displays them in her closet, up to ten tobes stacked on a shelf spanning the walls of her closet, a striking visual that is ingrained in my memory. Above the shelf a caption reads, "Homage to my mothers closet." A second shelf displayed what I refer to as an archived 1968 white tobe made in Switzerland. Information about this particular white tobe was provided alongside what the white tobe represents. The caption reads:

\section{White Abu-Gijaija Tobe Made in Switzerland.}

This white tobe is made of the highest quality cotton in one of the most popular style of tobes- Abu-Gijaija. Abu-Gijaija is known for the density of the dots and their texture. This tobe belongs to the mother of Alawia Al-Bakri from 1968.

All Sudanese women donned the iconic white tobe in the 1800s. By the 1950s the white tobe was the preferred uniform for the working Sudanese women and students. At the time, the white tobe was worn during funeral services and by a mourning woman.

In addition, I placed historical facts about the tobe on the back of postcards with four various abstract images of the tobe, for the audience to take.

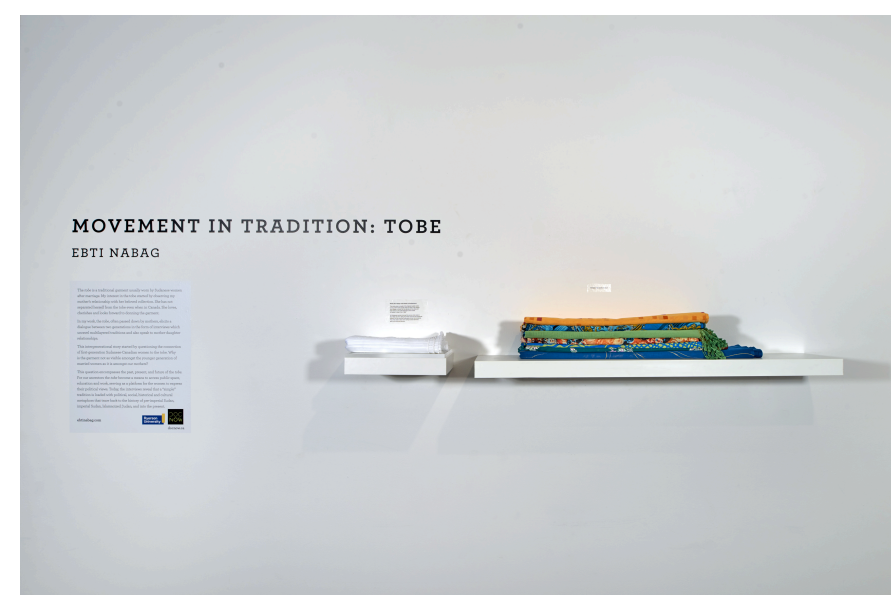

Figure 8: Movement in Tradition: Tobe, installation (C) Martin Franchi 


\section{CONCLUSION}

Overall, the process of creating the work and bringing the different elements and components of the exhibition together was a challenging one. Being open to editing out components of the show was something that I had to learn to accept. With all the critiques, opinions and challenges that were presented, over time it became easier to not be attached to individual pieces. The bigger picture of a well rounded exhibition that was not cluttered, not redundant in content that allowed the audience and the space to breathe was the main priority.

The positive reactions I received encourage me to possibly show it again in the future. In the past I pondered whether to include an archival component in the show. If an opportunity presents itself, I will explore the archival component further, and reconsider using the portraits instead of the abstract pictures. If I continue showing the abstract images, with 20 to choose from, the viewer is able to see something different during each exhibit. While the possibility of exhibiting the show once again or taking it to Sudan is something of interest, I am ready to move forward and start on a new project. Staying within the realm of my heritage, I hope to travel to Sudan and document the "tea ladies" who are found by the dozens on every street in Sudan. These mobile cafés are the equivalent to the many Tim Horton's easily found in every couple of streets in Canada. Being a tea lady is a business for the underprivileged. Tea and coffee are the basis of an undying culture in Sudan. With a large number of customers daily, these women are able to provide for their families, pay for their kid's education and even wedding expenses. Being exposed to video and employing the medium in my project, I hope to further build on my video techniques and create a 15-minute observational short film about the lives of the "tea ladies" in Sudan. Themes of Movement are found within this project: Sudan, culture, and an observational documentary. I mentioned this to lead with: I came into the program hoping to find my artistic voice and a style of documentary that will represent my work. I believe I am on that path, at least for now. 
Having come into the program with very little experience in documentary practice, I am leaving with a clear idea of how to create documentary work with substance that is able to bring exposure to topics, people and issues that otherwise might not get any, work that can bring people together and also help me grow as a documentarian. I am leaving this MFA program with the desire to keep creating and growing.

Word Count: 10434 


\section{BIBLIOGRAPHY}

Alcoff, Linda. "The Problem of Speaking for Others." Cultural Critique, no. 20 (1991): 5-32, p.7.

Bernal, Victoria. "Gender, Culture, and Capitalism: Women and the Remaking of Islamic "Tradition" in a Sudanese Village." Comparative Studies in Society and History 36, no. 1 pg.46.

Brandt, Amy, "Zineb Sedira", Brookyln Museum, https://www.brooklynmuseum.org/eascfa/feminist_art_base/zineb-sedira (accessed June 14, 16).

Brown, Marie Grace. 2014. "Fashioning their Place: Dress and Global Imagination in Imperial Sudan." Gender \& History 26 (3): 502-518.

Hayes, Rose Oldfield. "Female Genital Mutilation, Fertility Control, Women's Roles, and the Patrilineage in Modern Sudan: A Functional Analysis." American Ethnologist 2, no. 4 (1975).

Hynes, Nancy, and Picton John. "Yinka Shonibare." African Arts 34, no. 3 (2001): 60 95.

Hynes, Nancy, "Yinka Shonibare, Re-Dressing History”.Autumn 2001-African Arts.

Janice Boddy, Wombs, and Alien Spirits: Women, Men, and the Zar Culr in Northern Sudan (Madison: University of Wisconsin Press, 1989).

Jean Allman, 'Introduction, in Jean Allman (cd.), Fashion Africa: Power and the Politics of Dress (Bloomington: Indiana University Press, 2004), pp.1-4.

Lake,Nadine."Black Lesbian Bodies:Reflection on a Queer South African Archive. Africa Insight vol.44(1), 2014) 69-83. p.72.

McGonagle, Joseph, and Sedira Zineb. "Translating Differences: An Interview with Zineb Sedira." Signs 31, no. 3 (2006): 617-28. p.618.

Natsios, Andrew S. "Beyond Darfur: Sudan's Slide toward Civil War." Foreign Affairs 87, no. 3 (2008): 77-93. http://www.jstor.org/stable/20032652.

Nichols, Bill. "What Type of Documentary Are There?", Introduction to Documentary. Indiana University Press, (2001): 99-135. p.111.

Peter, Kok. "Sudan: Between Radical Restructuring and Deconstruction of State Systems." Review of African Political Economy 23, no. 70 (1996): 555-62. 
Renov, Michael. "Domestic ethnography and the construction of the 'other'self." Collecting visible evidence 6 (1999): 140-55.

Salih, Suad. "Sudanese Toub: Renewable world despite typical design. "SudanNow Magazine. March 2013. Accessed June 15, 2016. http://sudanow.info.sd/sudanese-toub-renewable-world-despite-typical design/.

Salley, Rael Jero. "Zanele Muholi's Elements of Survival." african arts 45, no. 4 (2012): 58-69, p.58.

Steiner, Christopher B. "Another Image of Africa: Toward an Ethnohistory of European Cloth Marketed in West Africa, 1873-1960." Ethnohistory 32, no. 2 (1985): 91-110.

tradition. Dictionary.com. Dictionary.com Unabridged. Random House, Inc. http://www.dictionary.com/browse/tradition (accessed: June 14, 2016).

tradition. Merriam-Webster.com. Merriam-Webster's Learner's Dictionary. http://www.merriam-webster.com/dictionary/tradition (accessed: June 14,2016).

Zenkovsky, Sophie. "MARRIAGE CUSTOMS IN OMDURMAN." Sudan Notes and Records 26, no. 2 (1945): 241-255, here p.241.

J. W. Crowfoot, "Wedding Customs in the Northern Sudan", Sudan Notes and Records 5 (1922),pp.1-28, here p.1. 